MATEC Web of Conferences 11,01006 (2014)

DOI: $10.1051 /$ matecconf / 20141101006

(C) Owned by the authors, published by EDP Sciences, 2014

\title{
Effect of the addition of nanosilica on white cement hydration at $25^{\circ} \mathrm{C}$
}

\author{
I.F. Sáez del Bosque ${ }^{1}$, S. Martínez-Ramírez ${ }^{1,2}$, M. Martín-Pastor ${ }^{3}$ and M. Teresa Blanco-Varela ${ }^{\mathrm{a}}$ \\ ${ }^{1}$ Instituto de Ciencias de la Construcción Eduardo Torroja (IETCC-CSIC), Department of Cements and Recycling \\ Materials, Madrid, Spain \\ ${ }^{2}$ Instituto de Estructura de la Materia (IEM-CSIC), Madrid, Spain \\ ${ }^{3}$ Unidad de Resonancia Magnética, RIAIDT, edif. CACTUS, USC, Santiago de Compostela, Spain
}

\begin{abstract}
The cement industry is keen on reducing natural resource consumption, reusing waste that would otherwise be sent to a rubbish tip and lowering its $\mathrm{CO}_{2}$ emissions. In pursuit of those objectives, the addition of materials such as silica fume, ceramic waste, rice husk and precipitated or colloidal nanosilica, in the various stages of cement manufacture has become increasingly common. That practice inspired the present study (using isothermal conduction calorimetry, ${ }^{29} \mathrm{Si}$ and ${ }^{27} \mathrm{Al}$ MAS NMR, XRD and DTA/TG) of the effect of precipitated amorphous nanosilica (10 wt \%) on white portland cement (WPC) hydration. The isothermal conduction calorimetry findings, which were consistent with the NMR and DTA/TG results, showed that adding amorphous nanosilica altered reaction kinetics, expediting alite and belite hydration. The addition also intensified the heat flow attributed to alumina phase hydration and brought the respective peak forward. Although no general consensus has been reached in the literature on the attribution of the third peak appearing on the calorimetric curve for WPC, based on the present findings, the main aluminate hydrate product is monosulfoaluminate. Furthermore, a pre-peak inflection point on the profile of the first exothermal peak on the WPC calorimetric curve was interpreted as the beginning of the pozzolanic reaction, which accelerates alite hydration, consuming portlandite and raising the heat released. C-S-H gel nanostructure was also modified. The results revealed a linear relationship in both the blended and the pure cement pastes between the degree of hydration and the number of $\mathrm{Q}^{1}$ and $\mathrm{Q}^{2}$ units in the gel. The presence of $\mathrm{Q}^{2}$ units was much greater and of $\mathrm{Q}^{1}$ units slightly lower in the former than in the latter.
\end{abstract}

\section{Introduction}

Portland cement is a multi-phase material consisting primarily of calcium silicates $\left(\mathrm{C}_{3} \mathrm{~S}\right.$ and $\mathrm{C}_{2} \mathrm{~S}$, known as alite and belite), tricalcium aluminate $\left(\mathrm{C}_{3} \mathrm{~A}\right)$, ferrite calcium aluminates $\left(\mathrm{C}_{4} \mathrm{AF}\right)$ and gypsum, which when mixed with water form a series of hydration products that induce cement paste hardening. Moreover, in recent years the cement industry has been progressively adding other materials (such as fly ash, silica fume and blast furnace slag) in the various stages of cement manufacture to comply with European sustainable development policies. Non-standardised additions (including ceramics, glass, or rice husk / sugar cane ash) are also being studied as possible components in cement manufacture [1-3] to lower the strain on natural resources, reuse waste that would otherwise be stockpiled in rubbish tips, and reduce atmospheric $\mathrm{CO}_{2}$ emissions. An understanding is therefore needed of how the presence of these additions affects hydration and consequently the properties of the end product. Moreover, since additions modify initial hydration, variations in very early age heat of hydration merits investigation. The present study therefore explored the effect of amorphous nanosilica (nSA) on early and late age white portland cement (WPC) hydration. The techniques used included isothermal conduction calorimetry, ${ }^{29} \mathrm{Si}$ MAS NMR, XRD and DTA/TG.

\section{Experimental}

The chemical composition of the BL I $52.5 \mathrm{R}$ (Spanish standard UNE 80305) white cement used in this study, determined by XRF, was: $65.08 \mathrm{wt} \% \mathrm{CaO} ; 21.71 \mathrm{wt} \%$ $\mathrm{SiO}_{2} ; 4.85$ wt $\% \mathrm{Al}_{2} \mathrm{O}_{3} ; 3.82$ wt $\% \mathrm{SO}_{3} ; 0.88$ wt $\% \mathrm{MgO} ;$ 0.57 wt $\% \mathrm{~K}_{2} \mathrm{O} ; 0.32$ wt $\% \mathrm{Fe}_{2} \mathrm{O}_{3} ; 0.15$ wt $\% \mathrm{Na}_{2} \mathrm{O} ; 0.12$ $\mathrm{wt} \% \mathrm{TiO}_{2} ; 0.06 \mathrm{wt} \% \mathrm{P}_{2} \mathrm{O}_{5}$ y LOI=2.39. The amorphous nanosilica (nSA) supplied by EQIL contained $90 \mathrm{wt} \%$ $\mathrm{SiO}_{2}$ as well as smaller proportions of other oxides: 0.68 wt $\% \mathrm{Al}_{2} \mathrm{O}_{3} ; 0.386$ wt $\% \mathrm{Na}_{2} \mathrm{O} ; 0.074$ wt $\% \mathrm{Fe}_{2} \mathrm{O}_{3} ; 0.059$ $\mathrm{wt} \% \mathrm{TiO}_{2}$.

White cement pastes were prepared with $10 \mathrm{wt} \% \mathrm{nSA}$ and a water/solid ratio of 0.66 , and cured at $25^{\circ} \mathrm{C}$ for 1 , 28,62 or 182 days (WPC + $10 \mathrm{wt} \% \mathrm{nSA}$ pastes). Unblended pastes (labelled WPC pastes) were prepared as a control in the same manner, although with a w/s ratio 
of 0.425 . Different $\mathrm{w} / \mathrm{s}$ ratios were needed to ensure similar workability and consistency in the two types of pastes, to compensate for the very high water demand in nSA.

The pastes were characterised by XRD, ${ }^{29} \mathrm{Si}$ and ${ }^{27} \mathrm{Al}$ $\mathrm{CP} / \mathrm{MAS} \mathrm{NMR}$, DTA/TG and isothermal conduction calorimetry.

The $128{ }^{29} \mathrm{Si}$ MAS NMR scans performed were run on a BRUKER AVANCE-400 (9.4 T) spectrometer operating at a frequency of $79.4 \mathrm{MHz}$, with a $7-\mu$ s pulse width, a 60 -s recycle delay and a $4 \mathrm{kHz}$ spinning rate. All the ${ }^{29} \mathrm{Si}$ spectra were recorded with TPPM proton decoupling at $\gamma \mathrm{B}_{1} / 2 \pi$ field of $2.5-\mathrm{kHz}$ during FID acquisition. The ${ }^{27} \mathrm{Al}$ MAS NMR experiments were conducted using a $2-\mu \mathrm{s} \pi / 2$ pulse width, a 5-s recycle delay, 400 scans and a $10 \mathrm{kHz}$ spinning rate. ${ }^{27} \mathrm{Al}$ Crosspolarization spectra were collected with contact time of 2-ms. Kaolin $(\delta=-91.5 \mathrm{ppm})$ and $\mathrm{AlCl}_{3} \cdot 6 \mathrm{H}_{2} \mathrm{O}(\delta=0$ $\mathrm{ppm})$ solution were respectively used as the references for the ${ }^{29} \mathrm{Si}$ and ${ }^{27} \mathrm{Al}$ chemical shifts relative to the standard, TMS.

Powder X-ray diffraction (XRD) studies were conducted on a Bruker D8 Advance diffractometer, consisting of a high voltage, $3-\mathrm{kW}$ generator, a (1.54- $\AA$ $\mathrm{CuK} \alpha$ ) copper anode X-ray tube normally operating at $1.54 \mathrm{kV}$ and $50 \mathrm{~mA}$, a Lynxeye detector with a $3-\mathrm{mm}$ anti-scatter slit and a (0.5-\%) Ni K-beta filter. It was not fitted with a monochromator (i.e., $\mathrm{K} \alpha_{2}$ was not eliminated). Readings were recorded at $2 \theta$ diffraction angles ranging from 5 to $60^{\circ}$, with a step size of $0.019^{\circ}$ and a count time per step of $0.5 \mathrm{~s}$.

Calorimetric measurements were recorded at $25^{\circ} \mathrm{C}$ on a Thermometric (TAM Air) analyser. Water was the reference used, in amounts as needed to equal the heating capacity of the paste studied. The pastes were mixed for 3 minutes immediately prior to filling the vials and placing the samples in the calorimeter, where measurements were recorded for 72 hours. All the calorimetric curves in this paper are referred to gram of solid (for both pure and mixed samples), not to the total weight of the paste sample. The dissolution peak on each curve was not studied, given the difficulty of recording this parameter in ex-situ preparations.

\section{Results and discussion}

\subsection{Early age hydration}

The normalised heat flow curves for the two cement pastes (Figure 1) exhibited three more or less intense peaks. The addition of $\mathrm{nSA}$ to the cement was observed to induce a substantial change in the early age curve profile.

The XRD patterns (Figure 2) showed that during the pre-induction and induction periods, $\mathrm{C}_{3} \mathrm{~S}, \mathrm{C}_{3} \mathrm{~A}$ and gypsum dissolved, while ettringite (AFt) appeared as the primary reaction product (although a certain amount of portlandite also formed in this stage). Adding nSA reduced the induction period and raised the heat flow during that period (Table 1).

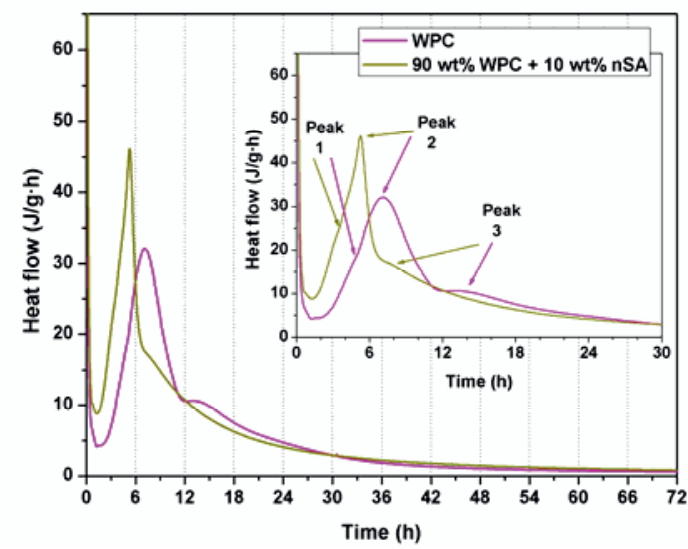

Figure 1. Normalised heat flow for hydrated white cement pastes with and without $\mathrm{nSA}$, cured at $25^{\circ} \mathrm{C}$

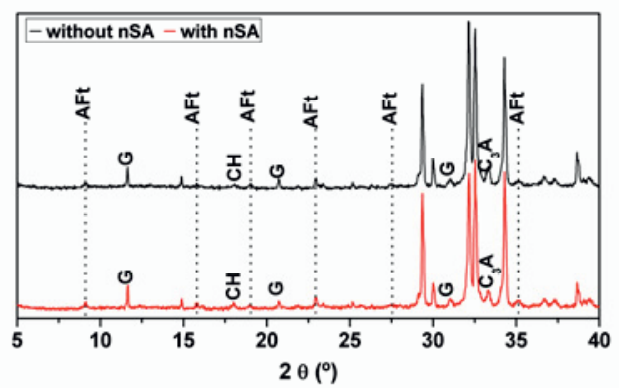

Figure 2. Induction period diffractograms for unblended paste and paste containing $10 \% \mathrm{nSA}$

Table 1. Induction period (calorimetric findings)

\begin{tabular}{|l|c|c|}
\cline { 2 - 3 } \multicolumn{1}{c|}{} & Time $(\mathrm{h})$ & Heat flow $(\mathrm{J} / \mathrm{g} \cdot \mathrm{h})$ \\
\hline WPC & $1.4 \pm 0.1$ & $4 \pm 1$ \\
\hline WPC $+10 \mathrm{wt} \% \mathrm{nSA}$ & $1.2 \pm 0.1$ & $8.56 \pm 0.2$ \\
\hline
\end{tabular}

The rise in the heat flow observed at the end of the induction period was attributed to accelerated portlandite precipitation and C-S-H gel formation. The curves for both blended and unblended pastes exhibited a shoulder prior to peak 2 (labelled peak 1). The XRD and ${ }^{27} \mathrm{Al}$ CP/MAS NMR findings (Figures 3 and 4, respectively) showed that the formation of $\mathrm{AFt}$, the sole aluminate hydrate in both pastes, was associated with aforementioned peak 1. The XRD patterns further showed that the ratio between the AFt phase diffraction line $\left(9.01^{\circ}\right)$ and the line for scantly reactive belite $\left(31^{\circ}\right)$ was considerably higher at peak 1 than during the induction period. The heavier heat flow and early appearance of peak 1 induced by $\mathrm{nSA}$ were not due exclusively to AFt formation, however. Rather, they also denoted the initiation of the pozzolanic reaction that accelerates alite/belite hydration via portlandite $(\mathrm{CH})$ consumption to generate additional C-S-H gel. Peak 1, then, was generated by two simultaneous C-S-H gelforming reactions:

$$
\begin{aligned}
& \mathrm{C}_{3} \mathrm{~S}+\mathrm{H}_{2} \mathrm{O} \rightarrow \mathrm{C}-\mathrm{S}-\mathrm{H}_{\mathrm{A}} \text { gel } \\
& \mathrm{CH}+\mathrm{nSA} \rightarrow \mathrm{C}-\mathrm{S}-\mathrm{H}_{\mathrm{B}} \text { gel. }
\end{aligned}
$$

$\mathrm{C}-\mathrm{S}-\mathrm{H}_{\mathrm{A}}$ gel formation was induced more intensely, since the XRD data showed larger amounts of $\mathrm{CH}$ in the paste containing nSA than in the control. 


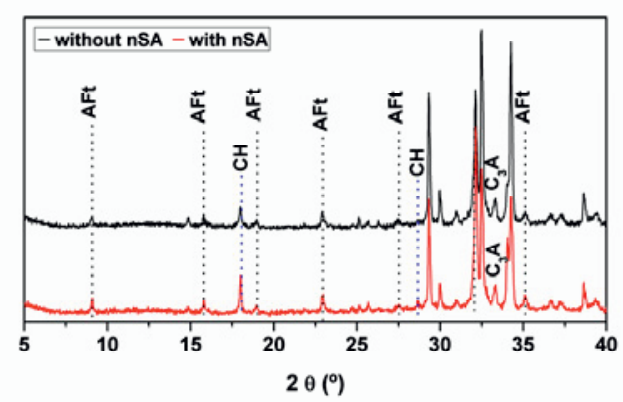

Figure 3. Peak 1 diffractograms for unblended paste and paste containing $10 \% \mathrm{nSA}$
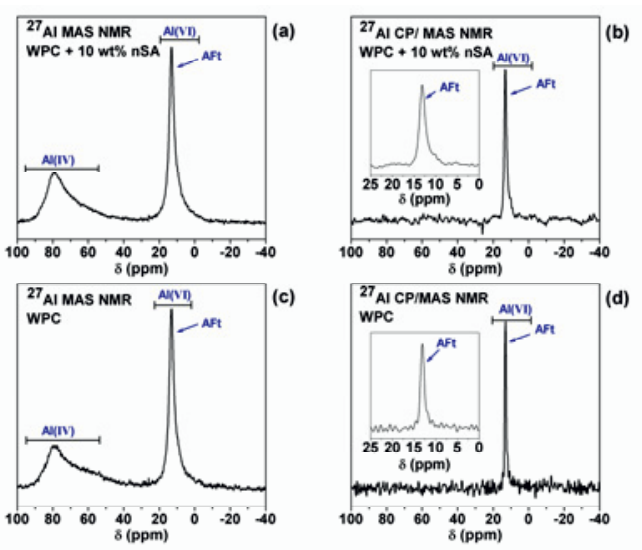

Figure 4. (a) and (c) ${ }^{27} \mathrm{Al}$ MAS NMR, and (b) and (d) ${ }^{27} \mathrm{Al}$ CP/MAS NMR spectra: for calorimetric curve peak 1 pastes with and without nSA

The second calorimetric peak was associated with silicate hydration (silicate reaction peak), whose kinetics are controlled by C-S-H gel nucleation and densification, as well as by portlandite precipitation. The heat flow curve for the paste containing nSA had a higher slope, i.e., a shorter acceleration period than the curve for the control (3.7 and $5.7 \mathrm{~h}$, respectively) and showed greater total heat released (Table 2). That denoted acceleration of the silicate phase hydration reactions in the presence of $\mathrm{nSA}$, a result of the reaction between the portlandite generated in silicate hydration and nSA to yield additional C-S-H gel. Further to findings reported by Thomas et al. [4], that C-S-H gel then seeded the formation of yet more C-S-H gel from the silicates present in the cement..

Table 2: Isothermal conduction calorimetry findings for white cement hydration, with and without nSA

\begin{tabular}{|l|c|c|}
\cline { 2 - 3 } \multicolumn{1}{c|}{} & WPC & $\begin{array}{c}\text { WPC }+ \\
10 \mathrm{wt} \% \mathrm{nSA}\end{array}$ \\
\hline Peak 1-Time (h) & $4.9 \pm 0.4$ & $3.75 \pm 0.05$ \\
\hline Peak 1 - Heat flow (J/g.h) & $19 \pm 3$ & $33 \pm 7$ \\
\hline Peak 2 - Time (h) & $7.4 \pm 0.4$ & $5.5 \pm 0.3$ \\
\hline Peak 2 - Heat flow (J/g.h) & $33 \pm 5$ & $52 \pm 3$ \\
\hline Peak 3 - Time (h) & $13.1 \pm 0.2$ & $6.9 \pm 0.2$ \\
\hline Peak 3 - Heat flow (J/g.h) & $12 \pm 1$ & $18 \pm 1$ \\
\hline
\end{tabular}

The pozzolanic reaction induced by $\mathrm{nSA}$ lowered the concentration of $\mathrm{Ca}^{2+}$ ions in the solution, leading to redissolution of $\mathrm{C}_{3} \mathrm{~S}$ and consequently contributing to greater total heat. Further to the XRD pattern, in this period the nSA-containing paste had clearly smaller amounts of portlandite than the control (Figure 5). Peak 2 was also observed to narrow as a result not only of the shorter acceleration period as noted earlier, but also of the shorter deceleration time, a possible indication that the C-S-H gel precipitated quickly in the presence of nSA.

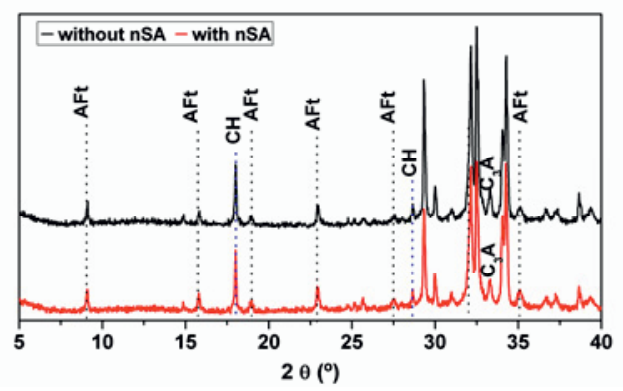

Figure 5. Peak 2 diffractograms for unblended paste and paste containing $10 \% \mathrm{nSA}$

Finally, according to the literature, the assignment of peak 3, which appeared at an earlier hydration time in the presence of nSA, is less straightforward. Traditionally associated with the conversion of $\mathrm{AFt}$ into monosulfoaluminate (AFm) [5-6], in recent years it has been attributed to the re-dissolution of sulfate ions that had previously been adsorbed onto the C-S-H gel. This new source of sulfates in the medium would react with $\mathrm{C}_{3} \mathrm{~A}$ to form AFt (secondary ettringite formation) [7-9]. This peak is sometimes referred to as the sulphate depletion peak because it marks the point at which the heat released is generated by $\mathrm{C}_{3} \mathrm{~A}$ dissolution and ettringite precipitation [10]. In this study, peak 3 appeared in the period associated in the literature with secondary ettringite formation. Its profile, however, resembled the profile for ettringite conversion to monosulfoaluminate. For that reason, peak 3 was analysed with other instrumental techniques to determine the reactions that gave rise to the signal in the pastes studied.

According to the XRD findings in Figures 2, 3, 5 and 6 for the pastes with and without $n S A, C_{3} A$ was consumed from the outset, while the amount of AFt rose peak 2 was reached. Gypsum, in turn, was depleted during peak 1 . In other words, after peak 2, phase AFm could have formed in a reaction involving $\mathrm{AFt}, \mathrm{C}_{3} \mathrm{~A}$ and water. AFm was only observed to form in the unblended paste, however, and not in the paste containing the addition, whose diffractogram exhibited a very high intensity diffraction line for $\mathrm{C}_{3} \mathrm{~A}\left(2 \theta=33.3^{\circ}\right)$. Moreover, in the diffractogram for peak 3 in the paste without $\mathrm{nSA}$, the AFt $\left(2 \theta=9.10^{\circ}\right) /$ belite $\left(2 \theta=31^{\circ}\right)$ ratio was lower than the ratio at peak 1 . This finding is consistent with AFm formation. In the pastes without nSA, AFm was observed to form at earlier ages than reported by Quennoz et al. [8] and Bullard et al. [9], which would therefore rule out the possibility of a secondary AFt precipitation in this type of pastes. The absence of any crystalline AFm on the diffractograms for the pastes containing nSA might support the assumption, put forward by other authors [89], that the main reaction generating peak 3 in the nSA- 
containing samples consisted of $\mathrm{C}_{3} \mathrm{~A}$ hydration with sulfates de-adsorbed off the C-S-H gel to form AFt.

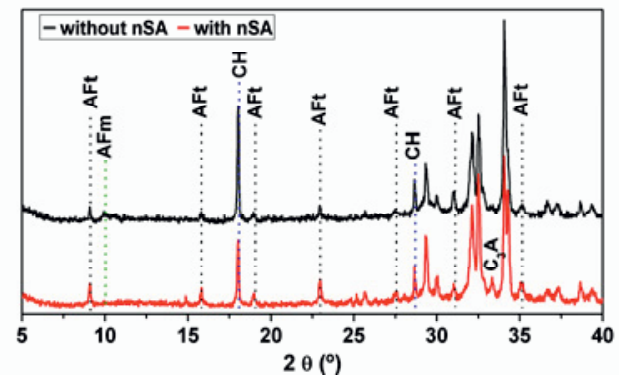

Figure 6. Peak 3 diffractograms for unblended paste and paste containing $10 \% \mathrm{nSA}$

The ${ }^{27}$ Al MAS NMR spectra for the two pastes (with and without $\mathrm{nSA}$ ) reproduced in Figures 7(a) and 7(c) contained two signals in the octahedral $\mathrm{Al}^{3+}$ range $(0$ to $20 \mathrm{ppm})$, one at around $13.2 \mathrm{ppm}$ and another at around $9.5 \mathrm{ppm}$, respectively associated with AFt and AFm [1112]. Both signals were more distinctly visible in the ${ }^{27} \mathrm{Al}$ CP/MAS NMR spectra (Figures 7(b) and (d)). The intensity of these signals on the ${ }^{27} \mathrm{Al}$ MAS NMR spectra varied substantially depending on paste composition. The conclusion that may be drawn is that $\mathrm{nSA}$ favoured $\mathrm{AFt}$ phase stability, because the ratio between the intensity of the AFt and AFm peaks on the ${ }^{27} \mathrm{Al}$ MAS NMR spectra for the blended pastes was much higher than on the spectra for the unblended samples.
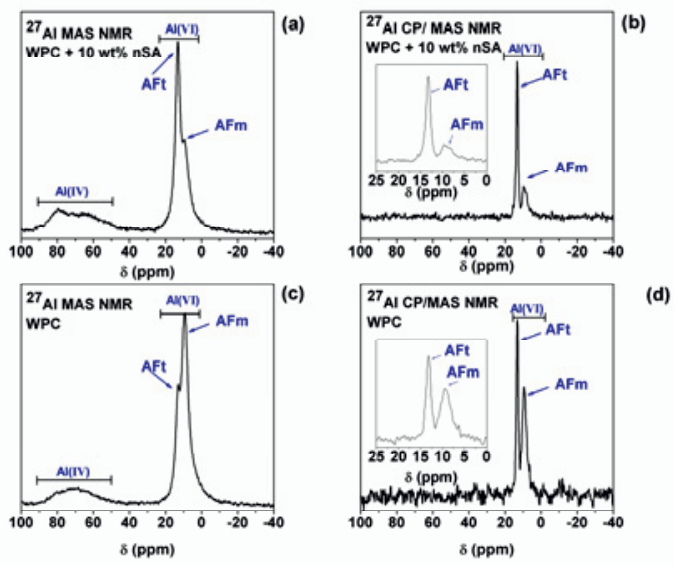

Figure 7. (a) and (c) ${ }^{27} \mathrm{Al}$ MAS NMR, and; (b) and (d) ${ }^{27} \mathrm{Al}$ CP/MAS NMR spectra: for calorimetric curve peak 3 pastes with and without nSA

Although $\mathrm{C}_{3} \mathrm{~A}$ is a minority phase in clinker, nSA has a perceptible effect on its hydration, which is retarded by the presence of the addition as shown in the diffractogram in Figure 6. The presence of $\mathrm{nSA}$ also induced AFt precipitation over a longer period of time, retarding or inhibiting AFm formation.

The hydration reaction in 24-hour pastes was also monitored by XRD (Figure 8), although no heat flow differences between the two pastes were observed in that period (Figure 1). The findings showed that in the nSAcontaining pastes, the $\mathrm{C}_{3} \mathrm{~A}$ phase disappeared entirely and the diffraction line for AFt was slightly less intense than on the peak 3 diffractogram. The small wide shoulder at around $2 \theta=10.78^{\circ}$ on the latter might be associated with calcium hemicarboaluminate $(\mathrm{Hc})$, although the possible formation of amorphous AFm cannot be ruled out. The diffractograms for the unblended pastes revealed that the AFm phase disappeared, giving rise to the formation of calcium hemicarboaluminate $(\mathrm{Hc})$ a result of the replacement of the $\mathrm{SO}_{4}{ }^{2-}$ groups in $\mathrm{AFm}$ with $\mathrm{CO}_{3}{ }^{2-}$ groups drawn from environmental $\mathrm{CO}_{2}$. According to Kuzel [13], that leads to a rise in the sulfate ions in the solution, thereby inducing further ettringite precipitation. The ${ }^{27} \mathrm{Al}$ MAS NMR spectra (Figure 9) contained a slightly asymmetric signal in the octahedral $\mathrm{Al}^{3+}$ range, which exhibited a much higher resolution on the ${ }^{27} \mathrm{Al}$ CP/MAS NMR spectra. The spectrum for the paste without nSA (Figures 9(a) and (b)) contained a signal for ettringite (AFt) at around $13.1 \mathrm{ppm}$ and a second signal with a $0.7 \mathrm{ppm}$ shift with respect to the AFm phase, i.e., at $10.2 \mathrm{ppm}$. In this study, the latter signal was associated with $\mathrm{Hc}$, which had been identified by XRD. No prior ${ }^{27} \mathrm{Al} \mathrm{CP} / \mathrm{MAS}$ NMR data were found for this compound.

The spectra for the pastes containing nSA (Figures 9(c) and (d)) showed that AFm (not clearly identified by $\mathrm{XRD}$ ) formed. In light of this proof that AFm is partially amorphous, quantitative methods such as XRD-Rietveld are scantly suitable for monitoring its behaviour as hydration advances.

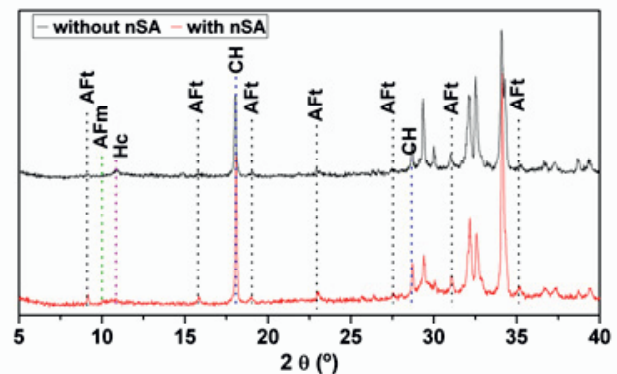

Figure 8. Diffractograms for 24-hour unblended paste and paste containing $10 \% \mathrm{nSA}$
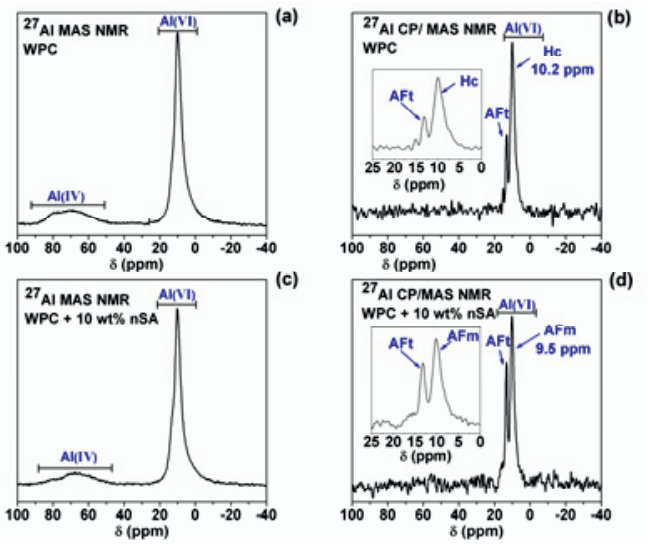

Figure 9. (a) and (c) ${ }^{27} \mathrm{Al}$ MAS NMR, and (b) and (d) ${ }^{27} \mathrm{Al}$ CP/MAS NMR spectra: for 24-hour pastes with and without nSA

\subsection{Effect of nSA on late age hydration}

A study of both the progress of the silicate phase hydration reactions and of the nanostructure of the C-S-H 
gel formed during the hydration of white cement with and without $10 \mathrm{wt} \% \mathrm{nSA}$ was conducted with ${ }^{29} \mathrm{Si}$ MAS NMR. A linear relationship was observed between the degree of hydration and the formation of C-S-H gel $\mathrm{Q}^{1}$ and $\mathrm{Q}^{2}$ units (Figure 10). Moreover, the C-S-H gel formed differed depending on the presence or otherwise of nSA: at a given degree of hydration, the gel formed in white cement blended with nSA had a larger number of $\mathrm{Q}^{2}$ units than the C-S-H gel formed in the unblended cement, while the $\mathrm{Q}^{1}$ units were less numerous in the former at degrees of hydration of approximately $50 \%$ or higher.

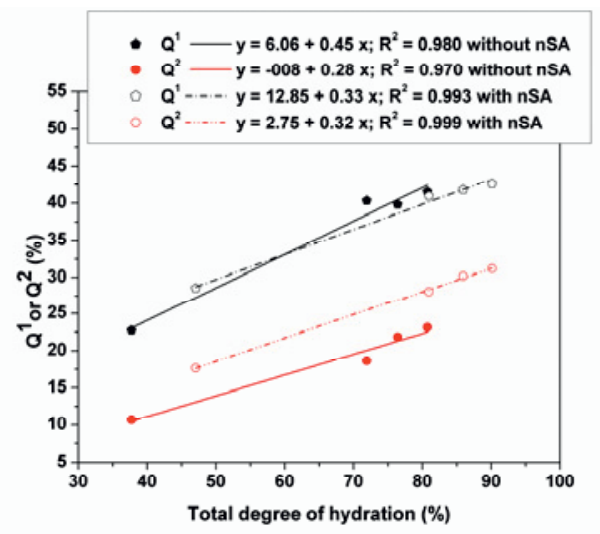

Figure 10. Linear relationship between the degree of hydration and the formation of $\mathrm{Q}^{1}$ and $\mathrm{Q}^{2}$ in the C-S-H gels formed

An earlier ${ }^{29} \mathrm{Si}$ MAS NMR study [14] on these samples showed that alite and belite hydration was expedited in the presence of nSA. This accelerating effect on silicate phase hydration was also observed in a ${ }^{29} \mathrm{Si}$ MAS NMR study of pure tricalcium silicate [15].

The analysis of the TG curves for the pastes showed that the amount of portlandite generated was smaller in pastes with $\mathrm{nSA}$, due to its depletion during the pozzolanic reaction. In the one-day material, however, the amount of portlandite was higher in the blended paste. This may very likely have been due to the fact, reported by some authors [16], that $\mathrm{nSA}$ can adsorb $\mathrm{Ca}^{2+}$ ions onto its surface, inducing $\mathrm{C}_{3} \mathrm{~S}$ re-dissolution and the concomitant formation of more C-S-H gel and portlandite, as per Equation 1. It further revealed that the water bonded to the $\mathrm{C}-\mathrm{S}-\mathrm{H}$ gel, defined as the total water loss less the loss in the $\mathrm{AFt} / \mathrm{AFm} / \mathrm{CH}$ phases, and carbonate loss of $\mathrm{CO}_{2}$ were greater in the pastes containing nSA (Figure 11).
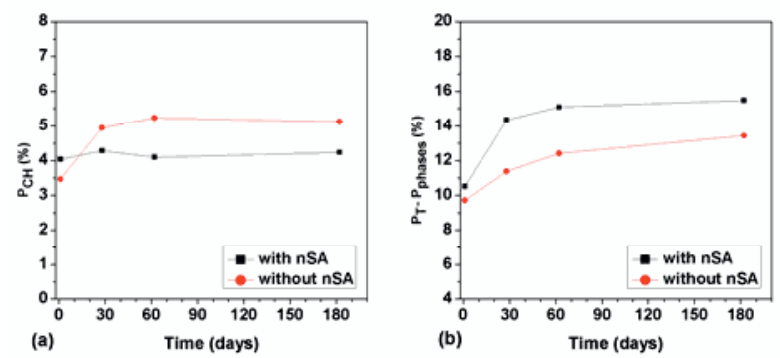

Figure 11. Percentage of (a) water loss in portlandite; and (b) bonded water loss taken up by the C-S-H gel generated during WPC hydration, in pastes with and without nSA $\left(\mathrm{P}_{\mathrm{CH}}=\right.$ dehydroxylation-induced mass loss in portlandite; $\mathrm{P}_{\mathrm{T}}=$ total mass loss at $1000^{\circ} \mathrm{C}$ ).

\section{Conclusions}

This study showed that early and late age white cement hydration rates changed in the presence of $\mathrm{nSA}$, a pozzolanic material with a small particle size. This substance shortened the induction period, accelerated silicate phase hydration and induced changes in the peaks associated with the formation of aluminate phases. The stabilisation of AFt formation retarded AFm formation but failed to stabilise Hc during early age hydration. The evidence gathered in this study showed that peak 3 on the calorimetric curve for unblended pastes was found to be generated by $\mathrm{AFm}$, rather than by secondary $\mathrm{AFt}$, precipitation.

${ }^{27} \mathrm{Al} \mathrm{CP} / \mathrm{MAS}$ NMR proved to be a suitable technique for studying the early age hydration of aluminate phases, which are difficult to detect with other techniques due to their poor crystallisation or low concentration.

In addition, changes in hydration kinetics are attendant upon changes in the $\mathrm{C}-\mathrm{S}-\mathrm{H}$ gel nanostructure: at degrees of hydration of $50 \%$ or higher, C-S-H gels containing larger numbers of $\mathrm{Q}^{2}$ and smaller numbers of $\mathrm{Q}^{1}$ units formed in the pastes with than without nSA.

\section{References}

1. C. Medina, P.F.G Banfill, M. Sánchez de Rojas and M. Frías. Constr. Build. Mater.,. 40(0): 822-831 (2013).

2. K.H. Tan and H. Du. Cem. Concr. Comp.. 35(1): 109-117 (2013).

3. G.C. Cordeiro, R. D. Toledo Filho, et al. Constr. Build. Mater,. 29(0): 641-646 (2012).

4. J.J. Thomas, H.M. Jennings and J.J. Chen. J. Phys. Chem. C, 2009. 113(11): 4327-43346. Taylor,

5. H.F.W. Taylor, Cement Chemistry (Thomas Telford, London, U.K., 1997).

6. J.R. Barnes, D.H. Clague, N.J. Clayden, C.M. Dobson, C.J. Hayes, G.W. Groves and S.A. Rodger. J. Mater .Scie. Letters. 4: 1293-1295 (1985).

7. A. Quennoz, K.L. Scrivener. Cem. Concr. Res. 42: 1032-1041 (2012).

8. A. Quennoz, K.L. Scrivever. Cem. Concr. Res.,. 44: 46-54 (2013).

9. J.W. Bullard, H.M. Jennings, R.A. Livingston, et al. Cem. Concr. Res. 41(12): 1208-1223 (2011).

10. D. Jansen, F. Goetz-Neunhoeffer, B. Lothenbach and J. Neubauer. Cem. Concr. Res. 42(1): 134-138 (2012).

11. J. Skibsted, E. Henderson and H.J. Jakobsen. Inor. Chem.. 32: 1013-1027 (1993).

12. M.D. Andersen, H.J. Jakobsen and J. Skibsted. Cem. Concr. Res. 36: 3-17 (2006).

13. H.J. Kuzel, Cem. Concr. Comp. 18: 195-203 (1996).

14. Sáez del Bosque, I.F. Thesis doctoral, Universidad Autónoma de Madrid, Madrid (Spain), July, 2012..

15. I.F. Sáez del Bosque, M. Martín-Pastor, S. MartínezRamírez and M.T. Blanco-Varela. J. Am. Ceram. Soc. 96: 957-965 (2013).

16. Y. Wei, W. Yao, X. Xing and M. Wu. Constr. Build. Mater. 36: 925-932 (2012). 